\title{
Organização do Poder Político: o estado constitucional em Niklas Luhmann
}

\author{
Rafael Lazzarotto Simioni ${ }^{1}$
}

\begin{abstract}
Resumo
Esta investigação procura descrever a ideia e a localização do Estado na teoria dos sistemas de Niklas Luhmann. Nessa perspectiva, o Estado é um sistema de organização do poder político que simboliza a unidade da diferença entre direito e política. O paradoxo do direito de resistência ao direito exigiu a organização do poder soberano na forma dos Estados de Direito. Mas a pergunta pela soberania do poder soberano manteve a necessidade de novos desdobramentos do paradoxo do poder político limitado e concentrado juridicamente. Para isso, surgiram as Constituições e uma nova configuração do Estado, na forma dos Estados Constitucionais.
\end{abstract}

Palavras-chave: Estado. Direito. Poder político. Teoria dos Sistemas. Niklas Luhmann.

\section{Introdução}

Diferentemente do caráter descentralizado dos centros de pesquisa para a ciência, dos bancos centrais para a economia, das escolas e universidades para a educação e das igrejas para a religião, a organização do poder político encontra suas referências sistêmicas em uma instância central, com abrangência politicamente delimitada através do conceito de soberania ${ }^{2}$. Nessa perspectiva, o Estado é entendido como um sistema de organização do poder político. Uma organização que simboliza a unidade da diferença entre direito e política.

Naturalmente, existem muitas perspectivas teóricas que negam a existência real de uma diferenciação entre os sistemas político e jurídico. Política e direito

\footnotetext{
${ }^{1}$ Doutor em Direito pela Unisinos, Mestre em Direito pela UCS, professor e pesquisador da Faculdade de Direito do Sul de Minas rafael@institutoorbis.org.br

${ }^{2}$ LUHMANN, Niklas. Politi cs and economy. Thesis eleven, [S.1], n. 53, p. 1-9, maio 1998.
} 
normalmente são tratados como se fossem um só sistema, identificado por meio da ideia de Estado. Com efeito, o Estado recebe tradicionalmente um conceito simultaneamente político e jurídico. Mas, ao contrário de provar uma falta de diferenciação entre política e direito, o conceito de Estado designa precisamente o paradoxo da unidade dessa diferença.

Obviamente há relações de interdependência entre política e direito. Afinal, a aplicação das decisões judiciais depende dos aparatos políticos organizados pelo Estado. E ao mesmo tempo, a pretensão de vinculação coletiva das decisões políticas depende da concentração do poder mediante a sua legitimação jurídica ${ }^{3}$.

No que segue, procuraremos explicitar a ideia e a localização do Estado dentro do desenho teórico da Teoria dos Sistemas de Niklas Luhmann.

Para tanto, essa investigação enfrentará a questão da fundamentação da política e do direito na Idade Média, de modo a explicitar os paradoxos que levaram Hobbes e Hume a deslocar o problema da fundamentação recíproca entre direito e política para a questão do direito de resistência. Em um segundo momento, a pesquisa introduz a ideia da soberania na forma de um paradoxo, cujo desdobramento deu ensejo à concepção moderna de Estado e à consequente clausura operativa do direito e da política na modernidade. E é exatamente dessa história de desdobramento criativo de paradoxos que surge o Estado Constitucional como símbolo da unidade da diferença entre política e direito.

Sustentamos, portanto, uma diferenciação radical entre os sistemas político e jurídico na modernidade, cuja unidade se mantém, contudo, por meio da simbolização simultaneamente política e jurídica do Estado Constitucional.

O método por meio do qual podemos observar esse tipo de dinâmica comunicativa da sociedade é a observação de segunda ordem da teoria dos sistemas autopoiéticos de Niklas Luhmann. E é importante sublinhar que se trata apenas de um modo de observação, não de uma proposição normativa que pretende solucionar algum problema concreto. Trata-se, antes, de uma forma de entendimento dessa complicada relação entre direito e política contemporânea, tendo o Estado Constitucional como símbolo - ou como acoplamento estrutural - dessa relação.

\footnotetext{
${ }^{3}$ LUHMANN, Niklas. El derecho de la sociedad. 2. ed. Trad. Javier Torres Nafarrate et al. Ciudad de México: Herder; Universidad Iberoamericana, 2005. p. 208.
} 
Essa questão dos paradoxos se torna importante para o direito, especialmente porque ela toca na questão da fundamentação da validade do direito, cuja história pode ser recontada na forma de uma história de desdobramentos criativos de paradoxos, para os quais, o Estado Constitucional constitui a mais atual - mas não a última - estratégia de resolução.

\section{Fundamentação da política e do direito na Idade Média}

Seguindo a perspectiva teórica de Niklas Luhmann, a diferença entre política e direito pode ser observada no tipo de comunicação que cada um desses sistemas produz na sociedade.

A política utiliza a comunicação do poder como seu meio de comunicação, enquanto o direito utiliza, como seu meio de comunicação, as normas jurídicas. Tanto o poder político quanto o direito se referem ao mesmo problema de referência: a correspondência entre a ação de alter e a ação de ego. Mas enquanto o poder resolve esse problema através do uso simbólico da ameaça de força física e outros recursos para vincular coletivamente, o direito resolve esse problema simbolizando expectativas normativas imunes a frustrações.

Política e direito referem-se, portanto, à comunicação de expectativas comportamentais. Ambos têm como problema de referência a correspondência entre uma ação de alter e uma ação de ego. Mas cada um produz modos diversos de solução para esse mesmo problema de referência: a política produz vinculação; o direito generaliza simbolicamente essa vinculação na forma de expectativas comportamentais.

E, precisamente, essa combinação da comunicação política com a comunicação jurídica possibilita à política produzir decisões coletivamente vinculantes, ao mesmo tempo em que possibilita para o direito a produção de expectativas normativas simbolicamente generalizadas.

Essa diferença entre poder político e direito manteve-se bastante clara por todo o período da Idade Média. Segundo Luhmann, a fundamentação da validade

\footnotetext{
${ }^{4}$ LUHMANN, Niklas. El derecho de la sociedad. 2. ed. Trad. Javier Torres Nafarrate et al. Ciudad de México: Herder; Universidad Iberoamericana, 2005. p. 474.
} 
do direito na ideia de direito natural foi a responsável por isso. Fundamentada no direito natural, a validade do direito não poderia depender do poder político do Império, da Igreja ou de outras autoridades terrenas ${ }^{5}$. E por isso, a sociedade medieval não dispunha das condições de possibilidade para simbolizar a unidade da diferença entre o direito e a ordem política dos Impérios.

Apesar das consolidações do direito romano, o sistema jurídico convivia nesse período com uma multiplicidade de direitos que, diferentemente de hoje, não se aplicavam para todos os estratos sociais. Havia um direito feudal, um direito das cidades, um direito dos reis, um direito canônico e também um direito civil profano ${ }^{6}$. Essa estratificação de direitos correspondia também a jurisdições específicas para cada tipo de direito. Existia, portanto, uma multiplicidade de direitos, separados segundo o critério dos estratos sociais, que correspondia a uma equivalente multiplicidade de jurisdições.

E, por esse motivo, no século XVI, começa a aparecer o problema de que não se poderia mais conceber o espaço soberano de um império sem um direito que valesse para todos, nem o espaço jurisdicional do direito sem a capacidade de imposição generalizada ${ }^{7}{ }^{8}$

A complexidade crescente da sociedade exigiu então dos Estados do início da Idade Moderna a unificação do direito válido em seus respectivos territórios, tornando possível a unificação também daquela multiplicidade de jurisdições. Só assim o problema da soberania pôde ser resolvido, pois a manutenção de direitos diferentes para estratos diferentes, submetidos também a jurisdições diferentes, tornava impossível um controle central e, portanto, uma submissão generalizada à soberania do império.

\footnotetext{
${ }^{5}$ LUHMANN, Niklas. La sociedad de la sociedad. Trad. Javier Torres Nafarrate. Ciudad de México: Herder, 2007. p. 765.

${ }^{6}$ LUHMANN, Niklas. El derecho de la sociedad. 2. ed. Trad. Javier Torres Nafarrate et al. Ciudad de México: Herder; Universidad Iberoamericana, 2005. p. 474-478.

${ }^{7}$ LUHMANN, Niklas. El derecho de la sociedad. 2. ed. Trad. Javier Torres Nafarrate et al. Ciudad de México: Herder; Universidad Iberoamericana, 2005. p. 475.

${ }^{8}$ Já em Hobbes se lê que "os pactos sem a espada não passam de palavras, sem força para dar a menor segurança a ninguém.” HOBBES, Thomas. Leviatã ou matéria, forma e poder de um estado eclesiástico e civil. Trad. João Paulo Monteiro e Maria Beatriz Nizza da Silva. São Paulo: Nova Cultura, 2004. p. 141.
} 
O direito unificado - com apenas uma jurisdição correspondente - permitiu então a organização e o controle da produção de normas sob uma instância central: o Estado moderno. Com um controle político centralizado da jurisdição e com a unificação dos direitos regionais - predominantemente consuetudinários o Estado moderno passou a exercer uma função de produção legislativa.

Surge, então, um "conceito político de lei" ${ }^{9}$. E isso significa que a distinção entre política e direito, mantida durante toda a Idade Média, começa a ganhar outro significado social. A razão política já não pode mais ser entendida como sinônimo de validade jurídica, mas, ao mesmo tempo, a política e o direito encontram sua unidade e sua fundamentação última no direito natural.

O paradoxo que a diferença entre política e direito produz é que somente do ponto de vista político se pode fundamentar tanto a política quanto o direito no direito natural. Pois do ponto de vista jurídico, somente se pode fundamentar a política e o direito na razão política. Esse paradoxo manteve-se escondido na semântica política da época através do problema do direito à resistência ${ }^{10}$. A questão era a de como justificar juridicamente uma resistência ao próprio direito, isto é, como justificar de modo juridicamente válido uma resistência ao próprio direito válido.

\section{0 direito de resistência ao direito em Hobbes e Hume}

Para Hobbes, o direito à resistência encontrava fundamento na necessidade da paz. Se cada um procurasse impor seu próprio direito, segundo a sua própria razão na tural, então o direito não garantiria a paz. Viver-se-ia em um "estado de natureza”, no sentido de Hobbes. ${ }^{11}$ A solução então foi construída na forma da ideia de autorização, conferida pelos súditos ao poder soberano de impor o direito de modo arbitrário.

9 LUHMANN, Niklas. El derecho de la sociedad. 2. ed. Trad. Javier Torres Nafarrate et al. Ciudad de México: Herder; Universidad Iberoamericana, 2005. p. 476.

${ }^{10}$ LUHMANN, Niklas. El derecho de la sociedad. 2. ed. Trad. Javier Torres Nafarrate et al. Ciudad de México: Herder; Universidad Iberoamericana, 2005. p. 477.

${ }^{11}$ Pode-se ler em Hobbes: "não pode ser negado que o estado natural dos homens, antes de ingressarem em sociedade, era um estado de guerra e não uma guerra qualquer, mas sim uma guerra de todos contra todos." HOBBES, Thomas. Do cidadão. Trad. Fransmar Costa Lima. São Paulo: Martin Claret, 2006. p. 37. 
Sob a semântica do problema do direito à resistência, Hobbes esconde precisamente o paradoxo da fundamentação recíproca entre política e direito, isto é, o paradoxo da fundamentação política do direito e da fundamentação jurídica da política. Em Hobbes, esse paradoxo se mantém escondido através da questão do direito à resistência. $\mathrm{E}$ ao mesmo tempo, o paradoxo se desdobra através da ideia de autorização dos súditos ao soberano. ${ }^{12}$

Mas o paradoxo ficou desdobrado, e não resolvido, pela semântica política inaugurada por Hobbes. A questão de como o direito pode justificar pretensões jurídicas opostas sem recorrer a uma validade politicamente assegurada continuou presente na semântica política da época. Em outras palavras, o problema do paradoxo da justificação jurídica de pretensões jurídicas opostas permaneceu nas autodescrições da política. E, precisamente, em razão do “arbitrário" no poder soberano de Hobbes, no século XVIII e XIX vai surgir a ideia de que a função do Estado está na garantia da liberdade conforme ao direito: o Estado de Direito.

A concepção de Hobbes a respeito do Estado ilustra a dificuldade de se distinguir política e direito. Partindo de uma oposição entre Estado soberano e direitos individuais (naturais), Hobbes pôde fundamentar o direito no direito natural e a política no Estado soberano.

Assim, a partir do século XVIII, já não é mais necessário se recorrer a essa instância "natural" de fundamentação do direito e, por isso, inicia-se o processo de uma diferenciação funcional radical do sistema jurídico.

\footnotetext{
${ }^{12}$ Veja-se esta passagem do Leviatã: “designar um homem ou uma assembléia de homens como representante de suas pessoas, considerando-se e reconhecendo-se cada um como autor de todos os atos que aquele que representa sua pessoa praticar ou levar a praticar, em tudo o que disser respeito à paz e segurança comuns; todos submetendo assim suas vontades à vontade do representante, e suas decisões a sua decisão. Isto é mais do que consentimento, ou concórdia, é uma verdadeira unidade de todos eles, numa só e mesma pessoa, realizada por um pacto de cada homem com todos os homens, de um modo que é como se cada homem dissesse a cada homem: "Cedo e transfiro meu direito de governar-me a mim mesmo a este homem, ou a esta assembléia de homens, com a condição de transferires a ele teu direito, autorizando de maneira semelhante todas as suas ações". Feito isto, à multidão assim unida numa só pessoa se chama Estado, em latim civitas. É esta a geração daquele grande Leviatã, ou antes (para falar em termos mais reverentes) daquele Deus Mortal, ao qual devemos, abaixo do Deus Imortal, nossa paz e defesa." HOBBES, Thomas. Leviatã ou matéria, forma e poder de um estado eclesiástico e civil. Trad. João Paulo Monteiro e Maria Beatriz Nizza da Silva. São Paulo: Nova Cultura, 2004. p. 144.
} 
A partir de Hobbes, a semântica política passa a se preocupar mais com o problema do "arbitrário" na imposição política do direito do que com o problema da justificação dessa imposição. O poder soberano conferido pelos súditos não pode ser arbitrário. E por isso, uma imposição política arbitrária do direito justifica uma resistência.

David Hume é um dos pensadores políticos que utiliza esse argumento circular para desdobrar o paradoxo da fundamentação recíproca entre direito e política. E para desdobrá-lo, Hume teve que igualmente escondê-lo sob a forma do direito à resistência. ${ }^{13}$

Mas, diferentemente de Hobbes, Hume justifica o direito à resistência na verdade e na liberdade: "um direito sem solução possível seria coisa absurda, e assim, para esse caso, há a solução excepcional da resistência, sempre que se chegue à situação extrema de só por esse meio se poder defender a Constituição" ${ }^{14}$. E para decidir-se a respeito da justificação de uma resistência ao poder soberano, é utilizada a distinção aristotélica entre a virtude do poder soberano e a sua corrupção.

Assim, renunciando à ideia de um "contrato original" como fundamento do poder soberano, Hume tornou possível a justificação de um direito de resistência ao direito oficial do soberano com base na diferença entre práticas virtuosas do poder soberano, de um lado, e práticas corruptas, de outro. $^{15}$

${ }^{13}$ Em Hume se pode ler: "Admitindo-se, portanto a resistência em casos extraordinários, o único problema que merece ser discutido entre bons pensadores é qual o grau de necessidade capaz de justificar a resistência, tornando-a legítima e recomendável." HUME, David. Ensaios morais, políticos e literários. In: HUME, David. Investigação acerca do entendimento humano. Trad. João Paulo Gomes Monteiro e Armando Mora D’Oliveira. São Paulo: Nova Cultural, 2004. p. 214.

${ }^{14}$ HUME, David. Ensaios morais, políticos e literários. In: HUME, David. Investigação acerca do entendimento humano. Trad. João Paulo Gomes Monteiro e Armando Mora D’Oliveira. São Paulo: Nova Cultural, 2004. p. 215.

${ }^{15}$ A propósito, Hume escreve que: "uma teoria desse tipo é errônea [...]. A doutrina que baseia todo governo legítimo num contrato original, ou no consentimento do povo, pertence a este tipo". HUME, David. Ensaios morais, políticos e literários. In: HUME, David. Investigação acerca do entendimento humano. Trad. João Paulo Gomes Monteiro e Armando Mora D’Oliveira. São Paulo: Nova Cultural, 2004. p. 212. 
Precisamente, essa oposição entre direito válido e razão política constitui o problema fundamental do Estado Moderno ${ }^{16}$. É por isso que a diferença entre política e direito é concebida, nessa semântica política do início da Idade Moderna, sob a forma do problema da justificação dos atos de resistência contra o exercício do poder político soberano.

\section{A soberania do soberano e o estado de direito}

O pano de fundo dessas construções do início da Idade Moderna está sob o problema mais fundamental da unidade da diferença entre direito e política. O "soberano" personificou uma referência simbólica para justificar tanto a razão do poder político quanto a validade do direito.

Mas a fragilidade da ideia de soberano exigiu um deslocamento significativo da referência simbólica com a qual a política e o direito poderiam encontrar seus fundamentos. O símbolo "soberano" já não poderia produzir suficiente poder de vinculação coletiva se ele estava, ao mesmo tempo, submetido à vontade de Deus, à razão e ao direito.

E isso significa que a solução para o paradoxo da fundamentação recíproca entre direito e política foi um impulso de isolamento operacional entre os assuntos políticos e os assuntos jurídicos. O poder político já não poderia ficar sempre submetido às questões jurídicas, nem a jurisdição poderia continuar a sofrer interferências da política.

O valor da segurança jurídica exigia um isolamento operativo do direito em relação à política, como também o valor da razão política exigia um isolamento operativo da política em relação ao direito ${ }^{17}$. E ao mesmo tempo, o direito continuava a depender da política para o poder de imposição de suas decisões, enquanto a política também dependia do direito para conquis

\footnotetext{
${ }^{16}$ LUHMANN, Niklas. El derecho de la sociedad. 2. ed. Trad. Javier Torres Nafarrate et al. Ciudad de México: Herder; Universidad Iberoamericana, 2005. p. 479.

${ }^{17}$ LUHMANN, Niklas. La sociedad de la sociedad. Trad. Javier Torres Nafarrate. Ciudad de México: Herder, 2007. p. 767.
} 
tar legitimidade. O resultado dessa complexa oposição interdependente entre política e direito passou então a ser chamada de Estado de Direito ${ }^{18}$.

A organização política do poder, agora como Estado de Direito, passou a simbolizar uma instituição simultaneamente jurídica e política. Uma instituição ao mesmo tempo guiada por objetivos políticos e por normas jurídicas, que por isso tinha que operar exatamente entre as exigências de conformação normativa ao direito e as de realização dos objetivos políticos.

Os resultados desses desenvolvimentos refletiram, no século XIX, em um conceito de política fortemente conectado à ideia de Estado ${ }^{19}$. A política então já não poderia mais ser entendida como desvinculada do Estado. Segundo Luh$\operatorname{mann}^{20}$, foi exatamente essa compreensão da política como política estatal que fez possível o surgimento de partidos políticos organizados, com objetivos de ocupação de cargos públicos no Estado para a realização de finalidades políticas. E como a ideia de Estado simbolizava também o direito, a estruturação da política do Estado pôde ser realizada por meio de leis jurídicas.

Em outras palavras, mediante o símbolo "Estado de Direito" ${ }^{21}$, a política pôde usar o direito como seu principal meio de comunicação, isto é, como seu principal instrumento para a realização dos objetivos políticos. E ao mesmo tempo, o direito pôde usar o poder político estatal para garantir a efetividade de suas decisões ${ }^{22}$.

O resultado foi a criação de um processo circular de produção de normas jurídicas para a realização de objetivo políticos. E para corrigir os efeitos colaterais desse processo circular, gerava-se a necessidade de produção de mais normas

${ }^{18}$ LUHMANN, Niklas. El derecho de la sociedad. 2. ed. Trad. Javier Torres Nafarrate et al. Ciudad de México: Herder; Universidad Iberoamericana, 2005. p. 481.

${ }^{19}$ Vê-se, por exemplo, Hegel "Ma che cosa è diritto? È quel che enunciano le leggi; cé diritto, solo là dove esiste uno Stato." HEGEL, Georg Wilhelm Friedrich. Frammento del corso di filosofia del diritto 1831-1832 (10-11 novembre 1831). In: HEGEL, Georg Wilhelm Friedrich. Scritti storici e politici. Trad. Giovanni Bonacina. Roma: Laterza, 1997. p. 287.

${ }^{20}$ LUHMANN, Niklas. El derecho de la sociedad. 2. ed. Trad. Javier Torres Nafarrate et al. Ciudad de México: Herder; Universidad Iberoamericana, 2005. p. 482.

${ }^{21}$ LUHMANN, Niklas. Potere e codice politico. Trad. Gustavo Gozzi. Milano: Feltrinelli, 1982.

${ }^{22}$ LUHMANN, Niklas. Stato di diritto e sistema sociale. Trad. Flavio Spalla. Napoli: Guida, 1990b. 
jurídicas e assim, sucessivamente. ${ }^{23}$ Ao ser utilizado pelo poder político estatal, o direito produzia também conflitos sociais que já se apresentavam como problemas políticos para serem solucionados por meio de novas normas jurídicas.

A questão da origem das modificações do direito torna-se, então, importante tanto para a política quanto para o direito. Não se pode dizer que o direito é somente o resultado da política, nem que a política é uma mera derivação do direito. Mas então, como é possível entender a limitação jurídica da política e a dotação de força impositiva política ao direito?

A resposta para esse problema da unidade de uma diferença entre política e direito foi o Estado de Direito. Como símbolo da unidade de uma diferença, a ideia de Estado de Direito ocultou o paradoxo da fundamentação recíproca entre direito e política. Especialmente porque a pergunta pelo fundamento de legitimidade do Estado de Direito poderia ser respondida tanto apontando para o velho direito natural, como também para uma nova referência comunicativa: os procedimentos legais de criação do direito no âmbito do poder político estatal ${ }^{24}$.

Assim, a questão da origem das modificações do direito pôde ser tratada sob a fórmula das fontes do direito. E a questão da origem do poder político pôde ser tratada sob a fórmula da soberania do povo.

Com efeito, a partir do momento em que a questão da validade do direito passa a ser um problema especificamente jurídico de fontes válidas de produção de direito, o sistema jurídico já não precisa mais estabelecer uma dependência política para a justificação de sua normatividade simbolicamente generalizada.

E do mesmo modo, a partir do momento em que a questão da razão política passa a ser um problema especificamente político de soberania, o sistema político também já não precisa mais estabelecer uma dependência jurídica para a legitimação de suas decisões coletivamente vinculantes.

23 "El resultado es un fuerte incremento de material normativo. Las normas jurídicas se convierten en sedimento de la política ya acontecida que, cada vez, tiene más dificultades para volver a liquidar las nuevas ambiciones políticas". LUHMANN, Niklas. El derecho de la sociedad. 2. ed. Trad. Javier Torres Nafarrate et al. Ciudad de México: Herder; Universidad Iberoamericana, 2005. p. 482.

${ }^{24}$ LUHMANN, Niklas. Legitimação pelo procedimento. Trad. Maria da Conceição CôrteReal. Brasília: Universidade de Brasília, 1980. 
O direito já não pode mais ser entendido apenas como um instrumento para a realização de programas políticos, nem a política pode ser suficientemente entendida como um vetor de racionalidade na interpretação das normas jurídicas. Precisamente, a partir desse momento, a política e o direito conquistam clausura operativa. Para o direito, passa a importar apenas a distinção entre direito e não direito. E, para a política, passa a importar a distinção entre governo e oposição.

\section{Clausura operativa do direito e da política}

No mundo ocidental, esse momento histórico a partir do qual direito e política conquistam clausura operativa pode ser encontrado precisamente no início daquilo que hoje se entende por positivação do direito.

A positivação do direito deslocou o problema da validade transcendente do direito para o problema das fontes. $\mathrm{O}$ jusnaturalismo procurava fundar a validade do direito em ideais transcendentes (Deus, justiça, moral, ética). Mas a imutabilidade desses fundamentos de validade do direito logo se tornou incompatível com as exigências de uma sociedade industrial, quer dizer, uma sociedade que exigia um direito seguro e ao mesmo modificável para se adequar às constantes mudanças sociais.

A positivação do direito então resolveu também o problema das fontes. A validade do direito positivo não precisaria mais estar fundada em princípios morais ou em valores materiais ${ }^{25}$, porque, uma vez positivo, é o próprio direito que passa a estabelecer as condições de validade de si mesmo ${ }^{26}$.

Em outras palavras, o positivismo jurídico transforma o problema das fontes do direito em um problema secundário. Pois, no positivismo, só existe positivamente - o direito positivo. E a questão da validade material, social ou da

\footnotetext{
${ }^{25}$ Segundo Weber, a racionalidade do direito estaria fundamentada nas suas qualidades formais, onde então os desvios desse padrão de formalidade poderiam ser observados como uma materialização do direito. WEBER, Max. Economía y sociedad: esbozo de sociología comprensiva. 2. ed. Trad. José Medina Echavarría, et al. Bogotá: Fondo de Cultura Económica, 1977. v. 1. p. 653.

${ }^{26}$ LUHMANN, Niklas. El derecho de la sociedad. 2. ed. Trad. Javier Torres Nafarrate et al. Ciudad de México: Herder; Universidad Iberoamericana, 2005. p. 611.
} 
legitimidade do direito se resolve então pelo próprio direito positivo. Agora é o próprio direito que diz o que pode ser considerado direito existente e válido.

No paradigma positivista do direito, as fontes do direito já não estão mais ligadas a princípios morais, valores, consuetudes e normas fundadas em conteúdos transcendentes, como eram os axiomas jusnaturalistas. Ao contrário, as fontes do direito se esvaziam de conteúdos materiais e substituem-se por fontes formais.

E a forma com a qual o direito passa a produzir-se a si mesmo são os processos legislativos e judiciais ${ }^{27}$. Em outras palavras, no paradigma do positivismo jurídico, o problema das fontes do direito se desloca das referências transcendentes ao direito para o problema dos processos jurídicos de criação/aplicação do direito $^{28}$, pois fonte de direito válido é aquilo que o direito válido diz que é fonte de direito válido. E a saída dessa autologia só pode ser, então, a introdução de uma diferenciação temporal.

Estabelece-se, assim, uma sequencialização de atos, organizados na forma de procedimentos que vão constituindo a validade das decisões sobre a validade das normas. As decisões validam as normas e as normas validam as decisões, desde que estejam presentes as condições para que isso aconteça: um processo juridicamente válido de criação/aplicação do direito.

${ }^{27}$ LUHMANN, Niklas. Legitimação pelo procedimento. Trad. Maria da Conceição CôrteReal. Brasília: Universidade de Brasília, 1980.

${ }^{28}$ Isso fica já evidente em Windscheid "Quando è controverso se una legge sia stata emanata o debitamente pubblicata, non sapplicano quelle regole, che sono decisive per il caso in cui, in una controversia giuridica, un fatto è disputato fra le parti contendenti. Vige inece la massima che il giudice deve d'ufficio conoscere ed applicare il diritto. Se però la condizione delle cose fa che non si possa esigere dal giudice la cognizione della legge controversa, spetta alla parte che si richiama alla legge, di procurargliene la necessaria noticzia, se vuole che essa sia posta a base della decisione della controversia". WINDSCHEID, Bernardo. Diritto delle pandette. Trad. Carlo Fadda e Paolo Emilio Bensa. Milano: Torino Unione Tipografico, 1902. p. 49. E por isso, a respeito do direito consuetudinário, Windscheid conclui que "Quindi la legislaione attualmente è la fonte giuridica di gran lunga più importante; il diritto consuetudinario, di fronte al diritto legislativo, non occupa che un posto subordinato" WINDSCHEID, Bernardo. Diritto delle pandette. Trad. Carlo Fadda e Paolo Emilio Bensa. Milano: Torino Unione Tipografico, 1902. p. 53. Essa sensibilidade de Windscheid à positivação do direito o colocou em colisão com Savigny, Puchta, Böhlau, Bruns, Pfaff e Hofmann, para os quais o direito consuetudinário ocupa a primazia de fonte de direito diante do direito do Estado. Vê-se também, nesse contexto histórico, a discussão que Jhering faz contra Savigny e Puchta a respeito da origem do direito como "luta de interesses". JHERING, Rudolf Von. A luta pelo direito. 18. ed. Trad. João Vasconcelos. Rio de Janeiro: Forense, 1999. p. 8-9. 
É importante sublinhar essa transformação no direito da sociedade moderna, porque, antes do positivismo jurídico, os processos não tinham essa importância. Em um contexto de jusnaturalismo, por exemplo, a validade do direito estava na própria autoridade do representante do valor transcendente que conferia validade ao direito. Se a base de validade do direito era Deus, a autoridade dos seus representantes aqui na Terra era suficiente para conferir validade a decisões sobre essa ou aquela alternativa. Se a base de validade do direito eram os costumes comunitários, a comunicação da validade jurídica poderia circular nas decisões judiciais por meio da invocação das consuetudes locais.

E até mesmo ao tempo da jurisprudência de interesses na Alemanha, a validade do direito estava na proteção aos interesses legítimos. Assim, para garantir a validade de uma decisão judicial no contexto da jurisprudência de interesses, bastaria argumentar a legitimidade do interesse, já que só os interesses legítimos merecem proteção jurídica ${ }^{29}$. Ou ainda, se a base de validade do direito estivesse na vontade geral do povo, a autoridade do representante dessa vontade geral seria suficiente para validar as decisões. ${ }^{30}$

No positivismo - e nas sociedades secularizadas em geral - essas referências transcendentes perdem a autoridade. A positivação do direito torna-se incompatível com uma fonte de validade jurídica exterior ao próprio sistema jurídico. Em outros termos, a positivação do direito significa que não se tolera mais uma autoridade ou uma fonte de validade jurídica não prevista previamente pelo direito positivo como fonte válida de direito.

${ }^{29}$ O paradoxo é evidente: se os interesses que merecem proteção são apenas os interesses jurídicos, então "sólo los intereses jurídicamente dignos de protección disfrutan de protección jurídica". LUHMANN, Niklas. Observaciones de la modernidad: racionalidad y contingencia en la sociedad moderna. Barcelona: Paidós, 1997. p. 35.

${ }^{30}$ Hobbes já havia observado isso. Naturalmente, o Leviatã foi publicado em 1651, no contexto das lutas sociais e econômicas da Inglaterra. E na França, no mesmo Século de Hobbes, Pascal deixa o seguinte fragmento (fragmento 273): "Indubitavelmente, a igualdade dos bens é justa; mas, como não se podia fazer com que fosse forçoso obedecer à justiça, fez-se com que fosse justo obedecer à força; como não era possível fortalecer a justiça, justificou-se a força, a fim de que se juntassem o justo e o forte e se estabelecesse a paz, que é o sumo bem." HOBBES, Thomas. Leviatã ou matéria, forma e poder de um estado eclesiástico e civil. Trad. João Paulo Monteiro e Maria Beatriz Nizza da Silva. São Paulo: Nova Cultura, 2004; PASCAL, Blaise. Pensamentos. Trad. Pietro Nassetti. São Paulo: M. Claret, 2004. p. 165. 
Assim, os sistemas da política e do direito se diferenciam funcionalmente na medida em que passam a produzir modos diferentes de comunicação: a política comunica expectativas mediante o poder de vinculação coletiva, enquanto o direito comunica expectativas por meio da generalização simbólica de um caráter normativo a determinadas expectativas sociais. ${ }^{31}$

\section{A soberania dos estados constitucionais}

O problema da arbitrariedade soberana, desencadeado pela teoria política de Hobbes, ficou identificado com a figura do Estado, a partir da qual todas as demais arbitrariedades ganharam o sentido de arbitrariedades não-soberanas. Mas essa transcendentalização do paradoxo pela introdução do valor "Estado" não o resolveu, apenas deslocou o paradoxo para outros níveis.

Quer dizer, a resolução de um paradoxo só pode ser feita pela criação de outro: o da sujeição de um poder necessariamente não sujeitável ${ }^{32}$. Entre o arbítrio soberano e o não soberano, surge o Estado como o lugar no qual o poder poderia se submeter à soberania do próprio poder.

Surge, assim, a nova configuração do paradoxo do poder soberano: um poder soberano que se fundamenta em si mesmo para limitar-se a si mesmo. Naturalmente, esse paradoxo do poder submetido à soberania do próprio poder precisava de uma assimetrização, quer dizer, o Estado precisava de algo que lhe permitisse "saltar fora" do paradoxo. Algo exterior, um valor externo ao poder soberano que lhe permitisse justificar o exercício desse poder sem recorrer ao poder mesmo. $\mathrm{O}$ problema é que esse valor externo não poderia mais ser a vontade de Deus e nem

\footnotetext{
${ }^{31}$ Isso significa que a força normativa do direito não está em nenhuma superioridade ou "comando" como fonte da norma jurídica, mas no direito positivo mesmo. Nesse sentido também: MacCormick "Se essa concepção de justiça é ou não boa ou sólida, é uma questão que envolve princípios gerais de filosofia normativa do direito ou de filosofia moral, com relação aos quais poderia ser realizado um debate interessante. Na maior parte das vezes, porém, trata-se de um debate que não ocorre em tribunais de justiça porque o dever dos juízes de fazer justiça de acordo com a lei resolve a questão para eles." MACCORMICK, Neil. Argumentação jurídica e teoria do direito. Trad. Waldéa Barcellos. São Paulo: M. Fontes, 2006. p. 94.

${ }^{32}$ LUHMANN, Niklas. El derecho de la sociedad. 2. ed. Trad. Javier Torres Nafarrate et al. Ciudad de México: Herder; Universidad Iberoamericana, 2005. p. 546.
} 
uma ideia normativa da natureza. Exatamente para resolver esse problema surgiram as Constituições.

As Constituições puderam resolver satisfatoriamente o paradoxo do poder soberano do Estado. Diferenciando competências e atribuições funcionais, uma Constituição limita a arbitrariedade do poder soberano sobre si mesmo. O arbítrio do poder soberano do Estado encontra agora, na Constituição, uma programação condicional do tipo "se isso-então isto", quer dizer, encontra na Constituição uma conformação jurídica, que absorve a pressão explosiva da circularidade que fundamenta o poder soberano ${ }^{33}$.

O Estado passa a ser descrito, a partir de então, como Estado Constitucional. Somente assim, sob a forma do Estado Constitucional, a sociedade pôde converter o direito positivo em um meio de conformação política e, ao mesmo tempo, em um instrumento jurídico para a implantação de objetivos políticos ${ }^{34}$. Com efeito, a partir do momento em que o direito se fecha sobre si mesmo e que isso acontece também com o sistema político, ambos os sistemas conquistam a liberdade de desenvolvimento com autonomia ${ }^{35}$.

Na medida em que as Constituições funcionam como mecanismos de limitação das influências recíprocas entre direito e política, elas se tornam conquistas reais da sociedade. Até porque as Constituições resolviam dois problemas de justificação: de um lado, o problema da justificação jurídica do direito secularizado, isto é, do direito positivo, que não mais se fundamentava na vontade de Deus ou no direito natural; e de outro, resolvia também o problema da canalização das arbitrariedades na divisão dos poderes do Estado, já que com as Constituições, cada Poder do Estado só poderia tomar decisões vinculando aos demais Poderes se observasse as condições do direito ${ }^{36}$.

${ }^{33}$ LUHMANN, Niklas. Teoría política en el estado de bienestar. Trad. Fernando Vallespín. Madrid: Alianza, 1994. p. 36.

${ }^{34}$ LUHMANN, Niklas. El derecho de la sociedad. 2. ed. Trad. Javier Torres Nafarrate et al. Ciudad de México: Herder; Universidad Iberoamericana, 2005. p. 540.

${ }^{35}$ LUHMANN, Niklas. Essays on self-reference. New York: Columbia University Press, 1990a. p. 229.

${ }^{36}$ LUHMANN, Niklas. Teoría política en el estado de bienestar. Trad. Fernando Vallespín. Madrid: Alianza, 1994. p. 36. 
Canalizando e restringindo as possibilidades de influências políticas sobre o direito e, ao mesmo tempo, as possibilidades de influências jurídicas sobre a política, as Constituições permitiram graus maiores de liberdade recíproca na política e no direito. Em outras palavras, as Constituições excluíam todas as possibilidades que não se conformavam nelas, como por exemplo, a possibilidade de usar o direito de propriedade para obter poder político, como também a possibilidade de usar o poder político para obter direitos de propriedade.

As Constituições, em outros termos, produziam barreiras para a conversão direta do poder em dinheiro ou do dinheiro em poder ${ }^{37}$. Com as Constituições, a riqueza econômica já não poderia ser, ao mesmo tempo, um fato gerador de influência política. E nem a influência política deveria depender da riqueza econômica. Depois das Constituições, a corrupção política do soberano já poderia ser vista como um problema de inconstitucionalidade ${ }^{38}$.

Mas, ao mesmo tempo em que limitam as influências recíprocas entre direito e política, as Constituições também oportunizam aumentos recíprocos de irritabilidade, como por exemplo, uma maior possibilidade jurídica de se registrarem decisões políticas em forma jurídica (forma de leis válidas) e, ao mesmo tempo, uma maior possibilidade política de servir-se do direito para a realização concreta dos objetivos políticos ${ }^{39}$.

Para o direito, a Constituição é política. Para a política, a mesma Constituição é jurídica. E assim, o paradoxo da autoconstituição da Constituição - ou o paradoxo da Constituição sem um fundamento além de si mesmo - torna-se inofensivo tanto para o direito quanto para a política.

Mesmo que as decisões jurídicas sejam tomadas levando-se em conta finalidades políticas, a referência da decisão à diferença entre direito e não-direito garante a inserção dessa decisão na comunicação jurídica. E ainda que as decisões

\footnotetext{
${ }^{37}$ LUHMANN, Niklas. Poder. Trad. Mónica Talbot e Darío Rodríguez Mansilla. Barcelona: Anthropos; Ciudad de México: Universidad Iberoamericana; Santiago de Chile: Pontificia Universidad Católica de Chile, 1995. p. 143.

${ }^{38}$ LUHMANN, Niklas. Sociologia del rischio. Trad. Giancarlo Corsi. Milano: Bruno Mondadori, 1996. p. 151.

${ }^{39}$ LUHMANN, Niklas. El derecho de la sociedad. 2. ed. Trad. Javier Torres Nafarrate et al. Ciudad de México: Herder; Universidad Iberoamericana, 2005. p. 541.
} 
políticas sejam tomadas levando-se em conta as regras do direito, a referência da decisão à diferença entre governo e oposição mantém essa decisão no âmbito da comunicação política.

Isso significa que tanto a política quanto o direito, como dois sistemas funcionalmente diferenciados, já não podem mais ser utilizados para resolver problemas que escapam de seus respectivos âmbitos de competência funcional. O direito, por exemplo, já não pode mais ser utilizado para resolver problemas políticos - a não ser para sublimá-los da política por meio do seu deslocamento ao judiciário. Nem a política pode ser utilizada para resolver problemas jurídicos.

A judicialização da política ou a politização da jurisdição só podem se apresentar como problemas quando já se tem que supor a diferença funcional entre direito e política. A interpretação das leis ou da Constituição acontece sob a forma de teorias especificamente jurídicas de argumentação, a partir das quais o recurso à vontade ou à intenção do legislador tem um papel secundário na concreção do sentido normativo de um texto legal ou Constitucional. E também as estratégias de concretização das políticas públicas do Estado obedecem a programas políticos que têm o direito apenas como um instrumento de legitimação das decisões.

\section{Considerações finais}

Nessa perspectiva de diferenciação radical entre política e direito - que é uma perspectiva comum a todas as concepções sistêmicas - o Estado de Direito é entendido como um símbolo, uma organização do poder político que simboliza a unidade de duas perspectivas diferentes: a perspectiva do direito e a da política.

Assim, na perspectiva da teoria dos sistemas de Niklas Luhmann, o Estado de Direito é um sistema de organização do poder político que simboliza a unidade da diferença entre política e direito. E a simbolização da unidade dessa diferença está no fato de que o Estado de Direito organiza a força pública através da imposição de limites juridicamente definidos e, ao mesmo tempo, organiza o uso dos recursos políticos da força pública para a aplicação do direito.

Em outras palavras, o Estado de Direito organiza a comunicação do poder na forma do monopólio da força pública, realizando essa organização através da 
imposição de limites definidos pelo direito. E ao mesmo tempo, ele instrumentaliza o direito com o monopólio da força pública.

O Estado de Direito, como símbolo da diferença entre política e direito, permite que não haja espaços não ocupados pelo direito ${ }^{40}$. O mundo pode ser reconstruído pela comunicação jurídica sob a forma da diferença entre direito e nãodireito. E por isso, do ponto de vista do sistema do direito - e somente do ponto de vista do direito - o Estado de Direito é concebido como uma organização do poder político segundo os limites pré-estabelecidos pelo direito.

Mas enquanto esse mesmo Estado de Direito é entendido, na perspectiva do direito, como um poder limitado pelo direito, na perspectiva do sistema político, ele é entendido de um modo totalmente diferente: uma organização das formas de distinção entre opiniões divergentes, de modo a tornar possível a tomada de decisões coletivamente vinculantes.

Isso significa que, conforme se transita de um sistema de referência para outro, o mesmo Estado de Direito se reconstrói com sentidos totalmente diferentes, que paradoxalmente encontram seus respectivos fundamentos um no outro: para a política, o Estado de Direito tem um fundamento jurídico; para o direito, o mesmo Estado de Direito tem um fundamento político.

Para a política, o Estado de Direito disponibiliza a codificação da diferença entre o que é conforme e o que é desconforme ao direito. E para o direito, o mesmo Estado de Direito disponibiliza a organização do poder de imposição de decisões. Nesse aspecto, o Estado de Direito é um "parasita” - no sentido que Luhmann utiliza de Michel Serres ${ }^{41}$. Uma organização que vive em razão de uma diferença que lhe é externa.

\footnotetext{
${ }^{40}$ É conhecida, nesse sentido, a fórmula de Kelsen segundo a qual "uma conduta que não é juridicamente proibida é - neste sentido negativo - juridicamente permitida.” KELSEN, Hans. Teoria pura do direito. 6. ed. Trad. João Baptista Machado. São Paulo: M. Fontes, 2003. p. 46.

${ }^{41}$ SERRES, Michel. Le parasite. Paris: Grasset, 1980.
} 


\title{
Political power organization: the constitutional state in niklas luhmann
}

\begin{abstract}
This research want to describe the idea and location of the State according to Niklas Luhmann's system theory. In this perspective, the State is an organization system of the political power which symbolizes the difference unit between Law and Politics. The paradox of Law resisting to Law, required the sovereign power organization in the form of State of Law. However, the power sovereignty quest kept the necessity of having a new unfolding of the paradox of legally concentrated and limited political power. For so, Constitutions and a new State Configuration have arisen in the Constitutional manner.
\end{abstract}

Keywords: State. Law. Political power. System Theory. Niklas Luhmann.

\section{Referências}

HABERMAS, Jürgen. Teoría de la acción comunicativa II: crítica de la razón funcionalista. Trad. Manuel Jiménez Redondo. Madrid: Taurus, 1988.

HEGEL, Georg Wilhelm Friedrich. Frammento del corso di filosofia del diritto 1831-1832 (10-11 novembre 1831). In: HEGEL, Georg Wilhelm Friedrich. Scritti storici e politici. Trad. Giovanni Bonacina. Roma: Laterza, 1997, p. 287-293.

HOBBES, Thomas. Do cidadão. Trad. Fransmar Costa Lima. São Paulo: Martin Claret, 2006.

HOBBES, Thomas. Leviatã ou matéria, forma e poder de um estado eclesiástico e civil. Trad. João Paulo Monteiro e Maria Beatriz Nizza da Silva. São Paulo: Nova Cultura, 2004.

HUME, David. Ensaios morais, políticos e literários. In: HUME, David. Investigação acerca do entendimento humano. Trad. João Paulo Gomes Monteiro e Armando Mora D’Oliveira. São Paulo: Nova Cultural, 2004.

JHERING, Rudolf Von. A luta pelo direito. 18. ed. Trad. João Vasconcelos. Rio de Janeiro: Forense, 1999. 
KELSEN, Hans. Teoria pura do direito. 6. ed. Trad. João Baptista Machado. São Paulo: M. Fontes, 2003.

LUHMANN, Niklas. A Restituição do décimo segundo camelo: do sentido de uma análise sociológica do direito. In: ARNAUD, André-Jean; LOPES JR, Dalmir (Org). Niklas Luhmann: do sistema social à sociologia jurídica. Trad. Dalmir Lopes Jr., Daniele Andréa da Silva Manão e Flávio Elias Riche. Rio de Janeiro: Lúmen Júris, 2004.

LUHMANN, Niklas. El derecho de la sociedad. 2. ed. Trad. Javier Torres Nafarrate et al. Ciudad de México: Herder; Universidad Iberoamericana, 2005.

LUHMANN, Niklas. Essays on self-reference. New York: Columbia University Press, 1990a.

LUHMANN, Niklas. La sociedad de la sociedad. Trad. Javier Torres Nafarrate. Ciudad de México: Herder, 2007.

LUHMANN, Niklas. Legitimação pelo procedimento. Trad. Maria da Conceição Côrte-Real. Brasília: Universidade de Brasília, 1980.

LUHMANN, Niklas. Observaciones de la modernidad: racionalidad y contingencia en la sociedad moderna. Barcelona: Paidós, 1997.

LUHMANN, Niklas. Poder. Trad. Mónica Talbot e Darío Rodríguez Mansilla. Barcelona: Anthropos; Ciudad de México: Universidad Iberoamericana; Santiago de Chile: Pontificia Universidad Católica de Chile, 1995.

LUHMANN, Niklas. Politics and economy. Thesis eleven, [S.1], n. 53, maio 1998.

LUHMANN, Niklas. Potere e codice politico. Trad. Gustavo Gozzi. Milano: Feltrinelli, 1982.

LUHMANN, Niklas. Sociologia del rischio. Trad. Giancarlo Corsi. Milano: Bruno Mondadori, 1996.

LUHMANN, Niklas. Stato di diritto e sistema sociale. Trad. Flavio Spalla. Napoli: Guida, 1990b.

LUHMANN, Niklas. Teoría política en el estado de bienestar. Trad. Fernando Vallespín. Madrid: Alianza, 1994. 
MACCORMICK, Neil. Argumentação jurídica e teoria do direito. Trad. Waldéa Barcellos. São Paulo: M. Fontes, 2006.

PASCAL, Blaise. Pensamentos. Trad. Pietro Nassetti. São Paulo: Martin Claret, 2004.

SERRES, Michel. Le parasite. Paris: Grasset, 1980.

WEBER, Max. Economía y sociedad: esbozo de sociología comprensiva. 2. ed. Trad. José Medina Echavarría, et al. Bogotá: Fondo de Cultura Económica, 1977. v. 1.

WINDSCHEID, Bernardo. Diritto delle pandette. Trad. Carlo Fadda e Paolo Emilio Bensa. Milano: Torino Unione Tipografico, 1902. 
